ISSN: 1829-6750 Inovasi Kurikulum, Agustus 2009, Thn. 6 . Vol 6 Nomor: 2

\title{
EVALUASI KURIKULUM TINGKAT SATUAN PENDIDIKAN
}

\section{Dr. Hermana Somantrie, MA}

Abstrak: Prinsip utama dari evaluasi kurikulum yaitu bahwa untuk evaluasi kurikulum yang komprehensif harus secara sistematik mencakup seluruh aspek yang berkaitan dengan kurikulum, demikian pula dengan Kurikulum Tingkat Satuan Pendidikan (KTSP). Sudah banyak sekolah yang telah mengimplementasi-kan KTSP, baik yang dikembangkan secara mandiri maupun dengan cara mengadopsi atau mengadaptasi KTSP yang telah dibuat oleh pihak lainnya. Setelah melewati suatu periode waktu tertentu, KTSP perlu dievaluasi agar kekuatan dan kelemahannya dapat teridentifikasi. Hasil dari evaluasi tersebut dapat digunakan sebagai bahan pertimbangan bagi penyempurnaan KTSP di masa yang datang atau sebagai informasi yang dapat digunakan bagi perumusan kebijakan pendidikan khususnya berkenaan dengan kurikulum.

\section{A. Pendahuluan}

Evaluasi terhadap kurikulum karena hasilnya dapat (curriculum evaluation) dilakukan untuk mengetahui sejauhmana kekuatan dan kelemahan suatu kurikulum. Di Amerika Serikat, misalnya, evaluasi kurikulum dianggap sebagai suatu aktivitas yang sangat penting

digunakan bagi upaya peningkatan mutu dan pembaharuan dalam bidang pendidikan. Mengingat begitu pentingnya evaluasi kurikulum, The American Evaluation Association telah mengeluarkan satu set kode 
ISSN: 1829-6750 Inovasi Kurikulum, Agustus 2009, Thn. 6 . Vol 6 Nomor: 2

etik bagi para evaluator dalam bidang pendidikan yang dinamakan dengan "the Guiding Principles for Evaluators".

Prinsip-prinsip tersebut adalah sebagai berikut: (1) Systematic Inquiry: Evaluators conduct systematic, data based inquiries about whatever is being evaluated; (2) Competence: Evaluators provide competent performance to stakeholders; (3) Integrity/Honesty:

Evaluators ensure the honesty and integrity of the entire evaluation process; (4) Respect for People: Evaluators respect the security, dignity and selfworth of the respondents, program participants, clients, and other stakeholders with whom they interact; and (5) Responsibilities for General and Public Welfare: Evaluators articulate and take into account the diversity of interests and values that may be related to the general and public welfare.
Dengan adanya kode etik semacam itu, evaluasi kurikulum yang dilakukan oleh para evaluator yang handal akan menghasilkan informasi kekuatan dan kelemahan kurikulum yang akurat dan obyektif.

\section{B. Kebijakan dan Teori}

\section{Kebijakan Evaluasi KTSP}

Kurikulum Tingkat Satuan Pendidikan (KTSP), yang kita kenal sekarang ini dalam dunia pendidikan di Indonesia, adalah kurikulum operasional yang disusun dan diimplementasikan sendiri oleh satuan pendidikan atau sekolah. KTSP mulai diperkenalkan pada tahun 2006 seiring dengan pemberlakuan Standar Isi (SI) dan Standar Kompetensi Lulusan (SKL) yang menjadi acuan utama dalam pengembangan KTSP.

Sejak saat itu sudah banyak sekolah yang telah mengimplementasikan KTSP, 
ISSN: 1829-6750 Inovasi Kurikulum, Agustus 2009, Thn. 6 . Vol 6 Nomor: 2

baik yang dikembangkan secara mandiri maupun dengan cara mengadopsi atau mengadaptasi KTSP yang telah dibuat oleh pihak lainnya. Setelah melewati suatu periode waktu tertentu, KTSP perlu dievaluasi agar kekuatan dan kelemahannya dapat teridentifikasi. Hasil dari evaluasi tersebut dapat digunakan sebagai bahan pertimbangan bagi penyempurnaan KTSP di masa yang datang atau sebagai informasi yang dapat digunakan bagi perumusan kebijakan pendidikan khususnya berkenaan dengan kurikulum.

Secara kebijakan sebagaimana yang dinyatakan dalam Undang-Undang Nomor 20 Tahun 2003, evaluasi kurikulum merupakan salah satu aktivitas evaluasi pendidikan karena kurikulum merupakan salah satu komponen pendidikan. Hal itu tampak dalam pernyataan Pasal 1 Ayat (21) yang menjelaskan bahwa evaluasi pendidikan adalah kegiatan pengendalian, penjaminan, dan penetapan mutu pendidikan terhadap berbagai komponen pendidikan pada setiap jalur, jenjang, dan jenis pendidikan sebagai bentuk pertanggungjawaban penyelenggaraan pendidikan.

Dalam pasal-pasal selanjutnya tampak sangat jelas bahwa evaluasi kurikulum dianggap sebagai aktivitas evaluasi pendidikan yang sangat penting sebagaimana yang dinyatakan dalam Pasal 57 dan Pasal 58. Selengkapnya, pernyataan pasal-pasal tersebut adalah:
(a) Pasal 57 Ayat menyatakan bahwa evaluasi dilakukan dalam rangka pengendalian mutu pendidikan secara nasional sebagai bentuk akuntabilitas penyelenggara pendidikan kepada pihak-pihak yang berkepentingan; Ayat menyatakan bahwa evaluasi dilakukan terhadap peserta 
ISSN: 1829-6750 Inovasi Kurikulum, Agustus 2009, Thn. 6 . Vol 6 Nomor: 2

didik, lembaga, dan program pendidikan pada jalur formal dan nonformal untuk semua jenjang, satuan, dan jenis pendidikan; dan (b) Pasal 58 Ayat (1) menyatakan bahwa evaluasi hasil belajar peserta didik dilakukan oleh pendidik untuk memantau proses, kemajuan, dan perbaikan hasil belajar peserta didik secara berkesinambungan; Ayat (2) menyatakan bahwa evaluasi peserta didik, satuan pendidikan, dan program pendidikan dilakukan oleh lembaga mandiri secara berkala, menyeluruh, transparan, dan sistemik untuk menilai pencapaian standar nasional pendidikan.

Berdasarkan hal-hal tersebut di atas dapat disimpulkan bahwa evaluasi kurikulum mempunyai makna sebagai: (1) unsur pengendali mutu, (2) bentuk akuntabilitas, program evaluasi pendidikan, (4) pemantauan proses, kemajuan, dan perbaikan program pendidikan, aktivitas yang dilakukan oleh lembaga yang mandiri, dan (6) program yang harus diselenggarakan secara berkala, menyeluruh, transparan, dan sistemik untuk menilai pencapaian standar nasional pendidikan.

\section{Teori Evaluasi \\ Kurikulum}

Prinsip utama dari evaluasi kurikulum yaitu bahwa untuk evaluasi kurikulum yang komprehensif harus secara sistematik mencakup seluruh aspek yang berkaitan dengan kurikulum. Sejumlah teoritikus menawarkan modelmodel untuk evaluasi kurikulum yang telah mereka kembangkan, antara lain sebagaimana yang diuraikan berikut ini.

\section{a. Model Tyler}

Model penilaian kurikulum yang dikembangkan oleh Tyler (1950) dinamakan dengan Goal Attainment Model. Langkah-langkah pendekatan penilaian Tyler 
ISSN: 1829-6750 Inovasi Kurikulum, Agustus 2009, Thn. 6. Vol 6 Nomor: 2

adalah: (1) Mulai dengan penentuan tujuan penilaian. Tujuan ini harus menyatakan dengan jelas materi yang akan dinilai dalam kurikulum; (2) Memilih, mengubah, atau menyusun alat penilaian dan menguji

obyektivitas, realibilitas, dan validitas alat tersebut; (3) Gunakan alat penilaian untuk memperoleh data; (4) Bandingkan data yang diperoleh dengan hasil penilaian sebelumnya yang memperoleh data; (5) Analisa data untuk menentukan kekuatan dan kelemahan dari kurikulum dan jelaskan alasan dari kekuatan dan kelemahan tersebut; dan (6) Gunakan data untuk membuat perubahan yang dianggap perlu dalam kurikulum.

\section{b. Model Bloom, Hastings, dan Madaus}

Bloom, Hastings, dan Madaus (1971) dalam penilaian kurikulum me-ngembangkan model pe-nilaian sumatif dan formatif. Perbedaan pokok diantaranya sumatif dan formatif adalah (1) tujuan, (2) waktu, dan (3) tingkat generalisasi. Penilaian formatif adalah penilaian terhadap kualitas kurikulum yang dilakukan setiap saat atau terus menerus selama proses pelaksanaan kurikulum berlangsung.

Hasil penilaiannya digunakan sebagai data pelengkap dalam penilaian akhir keseluruhan pelaksanaan kurikulum. Sebaliknya, penilaian sumatif adalah penilaian menyeluruh yang dilakukan terhadap kualitas kurikulum pada akhir suatu periode pelaksanaan program kurikulum. Hasil penilaiannya digunakan sebagai pertimbangan akhir terhadap keberhasilan pelaksanaan kurikulum.

\section{c. Model Stufflebeam}

Stufflebeam (1971) dikenal dengan model penilaian yang ia namakan (1) context evaluation,

(2) input evaluation, (3) process evaluation, and (4) product evaluation, atau lebih populer 
ISSN: 1829-6750 Inovasi Kurikulum, Agustus 2009, Thn. 6 . Vol 6 Nomor: 2

dengan singkatan CIPP Model Evaluation.

Context evaluation adalah penilaian yang dilakukan terhadap segala hal yang menjadi precede atau antecedent (pendahulu) suatu program dan memiliki implikasi keberhasilan atau kegagalan dalam menjalankan program tersebut. Input evaluation adalah penilaian yang dilakukan terhadap segala hal yang mendukung terselenggaranya suatu program. Process evaluation adalah penilaian yang dilakukan terhadap aspek-aspek implementasi suatu program. Product evaluation adalah penilaian yang dilakukan terhadap hasil atau outcome atau capaian suatu program.

\section{d. Model Stake}

Stake (1967) mengembangkan suatu model penilaian kurikulum dengan nama Continguency-Conngruence Model (CCM) atau sering juga disebut dengan Countenance Model. Perhatian utama dalam model Stake adalah hubungan antara tujuan penilaian dengan keputusan berikutnya berdasarkan sifat data yang dikumpulkan. Stake melihat adanya ketidaksesuaian antara harapan penilai dan guru. Menurut Stake penilaian yang dilakukan oleh guru tidak akan sama hasilnya dengan penilaian yang dilakukan oleh ahli penilaian.

Model CCM dimaksudkan guna memastikan bahwa semua data dikumpulkan dan diolah untuk melengkapi informasi yang dapat digunakan oleh pemakai data. Hal ini berarti bahwa penilai harus mengumpulkan data deskriptif yang lengkap tentang hasil belajar murid dan data pelaksanaan pengajaran, dan hubungan antara kedua faktor tersebut. Di samping itu juga, jugment data harus dikumpulkan. Stake mengartikan judgment data adalah data yang berasal dari pertimbangan berbagai 
ISSN: 1829-6750 Inovasi Kurikulum, Agustus 2009, Thn. 6 . Vol 6 Nomor: 2

ahli mata pelajaran dan kelompok masyarakat yang berkepen tingan dengan kurikulum.

\section{e. Model Provus}

Provus

(1971;

1972)

mengembangkan suatu pendekatan yang menggabungkan penilaian dengan teori management. Model ini mencerminkan asumsi Provus bahwa penilaian kurikulum hendaknya memenuhi dua tujuan: (1) melengkapi suatu proses untuk pengembangan kurikulum; dan melengkapi suatu cara penilaian manfaat suatu kurikulum.

Provus menamakan model penilaiannya dengan the discrepancy evaluation model. Model ini membedakan antara pelaksanaan atau kenyataan dan patokan, dan perbedaan tersebut oleh Provus dinamakan discrepancy (perbedaan antara dua hal yang harusnya sama). Provus menyarankan

bahwa karakteristik model penilaian diskrepansi antara standar dan realitas ditandai dengan 5 karakteristik: (1) design, (2) installation,

(3) process, (4) product, dan (4) cost.

\section{Metodologi Evaluasi}

\section{Kurikulum}

Para evaluator harus secara hati-hati menentukan metodologi evaluasi kurikulum karena hal itu akan menentukan kualitas informasi yang diperlukan dari sasaran penilaian. Beberapa pertanyaan berikut ini perlu dipertimbangkan agar penilaian kurikulum memenuhi ketentuan ilmiah yang berlaku pada umumnya:

- What is the evaluation design?

- Why was this one chosen?

- What are the limits of this design?

- How were instruments selected?

- Are they the most appropriate available for 
ISSN: 1829-6750 Inovasi Kurikulum, Agustus 2009, Thn. 6. Vol 6 Nomor: 2

these students, this curriculum?

- How can validity and reliability be demonstrated?

- Were instruments developed by the staff?

- What was the development process?

- What was done to ensure the validity and reliability of the instruments?

- Were instructors trained to administer, score, and interpret the results of the testing instruments?

- How was this done?

- What was the schedule for data collection?

- When were instruments administered?

- Were all students measured, or were sapling procedures used?

- What other types of information were collected, by whom, and when?

- What was the purpose of the various data collected (e.g., context indicators, implementation indicators)?

\section{Ruang Lingkup Evaluasi Kurikulum}

Cakupan evaluasi kurikulum sangat tergantung pada informasi yang diinginkan atau dihasilkan dari penyelenggaraan evaluasi. Oleh karena itu, cakupan dapat berskala luas atau berskala sempit. Namun demikian, cakupan minimal yang dapat dijadikan sebagai acuan adalah sebagaimana yang diuraikan di bawah ini.

- Objectives-clarity; limits achievable and suitable for evaluation.

- Contents-appropriate levels for the students; modern integration with other elements; achieving the objectives, infusing variety and information dissemination so that it is able to cope with the individual differences. Some elements used for evaluation of content 
ISSN: 1829-6750 Inovasi Kurikulum, Agustus 2009, Thn. 6 . Vol 6 Nomor: 2

include:

teachers'

meetings, and views of inspectors, parents, as well as specialists.

- Methods of teaching and educational aids - asking students and teachers about the efficiency appropriate to the methods through questionnaires, observations, surveys, studies, and other evaluating teaching aids.

- Evaluating studentsthere are targeted classes to ensure achieving the objectives through essays, trends, achievement and attitude tests.

- Evaluating teachersteachers are evaluated with regard to their efficiency, extent of achieving and implementing the curriculum, weakness in scientific and methods of teaching aspects, knowledge and information. They are evaluated by: inspectors, reports, student opinions, self-evaluation, written tests to discover competencies.

\section{E. Pemanfaatan Temuan} Evaluasi Kurikulum

Temuan atau findings adalah jantungnya dari seluruh proses evaluasi kurikulum. Temuan akan sangat ditentukan oleh metodologi yang digunakan dalam evaluasi kurikulum. Jika instrumen yang digunakan relevan, sahih, dan valid, temuan tidak perlu diragukan lagi otentisitasnya dan dapat digunakan untuk berbagai kepentingan. Temuan dapat dimanfaatkan antara lain untuk berikut ini.

- To provide us with a database of information regarding pedagogical processes.

- To provide us with information and to facilitate decision-making regarding the curriculum and its elements. 
ISSN: 1829-6750 Inovasi Kurikulum, Agustus 2009, Thn. 6 . Vol 6 Nomor: 2

- The outcomes of evaluation are the basis for developing and modifying the curriculum.

- To discover ways of learning and finding the points of strength and weakness in the curriculum.

- To show students a productive pathway to learning.

- To discover the students' areas of strengths and weaknesses.

- To discover the aspects of teaching that require greater focus and efforts.

- To share with teachers all they need to learn to teach students better.

\section{F. Pelaporan Hasil Evaluasi}

Ketika menulis laporan hasil evaluasi kurikulum perlu mempertimbangkan beberapa hal sebagai bberikut:
- Address all points specified in the funding agency's guidelines,

- Avoid using technical terms or jargon,

- Write in the active voice,

- Use a visually appealing format, including tables and figures,

- Organize the findings around objectives or evaluation questions,

- Be objective, reporting both positive and negative findings.

Provide plausible explanations wherever possible,

- Speculate about findings only when the data or reasoned arguments justify such conjectures,

- Acknowledge the pitfalls encountered,

- Write one report that will meet the needs of various audiences, 
ISSN: 1829-6750 Inovasi Kurikulum, Agustus 2009, Thn. 6. Vol 6 Nomor: 2

- Solicit comments on the draft report from various audiences, and Present oral evaluation report(s) before finalizing the written document. 